\title{
Work and Energy Response of Prefabricated Concrete Structure under Earthquake Excitation: Kolej Delima UiTM Pulau Pinang
}

\author{
Mohd Samsudin Abdul Hamid,", Norul Mas Diyana Ahmad², Kay Dora Abd Ghani', \\ Adhilla Ainun Musir ${ }^{1}$, Daliah Hassan ${ }^{1}$, Siti Hafizan Hassan ${ }^{1}$ \\ ${ }^{1}$ School of Civil Engineering, College of Engineering, Universiti Teknologi MARA (MARA University of Technology), Cawangan \\ Pulau Pinang, Pulau Pinang, Malaysia \\ ${ }^{2}$ Mentrol Global Holdings Sdn Bhd, No 4, Jalan Penggawa U1/75, Taman Perindustrian Batu Tiga, 40150, Shah Alam, Selangor, \\ Malaysia
}

Received December 27, 2020; Revised July 24, 2021; Accepted August 9, 2021

\section{Cite This Paper in the following Citation Styles}

(a): [1] Mohd Samsudin Abdul Hamid, Norul Mas Diyana Ahmad, Kay Dora Abd Ghani, Adhilla Ainun Musir, Daliah Hassan, Siti Hafizan Hassan, "Work and Energy Response of Prefabricated Concrete Structure under Earthquake Excitation: Kolej Delima UiTM Pulau Pinang," Civil Engineering and Architecture, Vol. 9, No. 5A, pp. 10 - 18, 2021. DOI: 10.13189/cea.2021.091302.

(b): Mohd Samsudin Abdul Hamid, Norul Mas Diyana Ahmad, Kay Dora Abd Ghani, Adhilla Ainun Musir, Daliah Hassan, Siti Hafizan Hassan (2021). Work and Energy Response of Prefabricated Concrete Structure under Earthquake Excitation: Kolej Delima UiTM Pulau Pinang. Civil Engineering and Architecture, 9(5A), 10 - 18. DOI: 10.13189/cea.2021.091302.

Copyright $(2021$ by authors, all rights reserved. Authors agree that this article remains permanently open access under the terms of the Creative Commons Attribution License 4.0 International License

\begin{abstract}
An earthquake occurs at any place that is located along or nearby the Pacific Fire Ring. The differences of earthquake excitation depend on the magnitude and peak ground acceleration whether in low, medium or high region. Four different previous earthquake excitation records were adopted in this study namely Kunak, Bukit Tinggi, El-Centro and Pacoima Dam earthquakes to analyze the work and energy response of prefabricated concrete structure that was designed using BS8110. It was found that the structure did not experience damages under low Kunak and Bukit Tinggi earthquake excitations but minor damages under El-Centro and major damages under Pacoima Dam earthquake excitations. Major damage occurred at the connection of the structural element such as beam-column connection and slab-beam connection due to large energy dissipation, reducing the structural strength and stiffness. This study is important in developing the best retrofitting methods for the structures after-impact maintenance.
\end{abstract}

Keywords Reinforced Concrete Structure, Earthquake Excitation, Hysteresis Loop, Work and Energy Response

\section{Introduction}

Plate tectonics was developed and divided into six main plate tectonics which were Pacific Plate, American Plate, African Plate, Antarctic Plate, India Plate and Eurasian Plate with other smaller plates. Bangash (2011) stated that earthquake is a term used to describe radiated seismic energy caused by the slip movement, magmatic, volcanic activities or other sudden stress changes in the earth and a sudden slip on a fault as well as the resulting ground shaking. Sengupta and Li (2014) found that the structural fall with limited transverse reinforcement possesses poor energy dissipation characteristics when being subjected to repeated cyclic deformation. Hence, it resulted in a pinch hysteresis loop with possible sudden loss of lateral capacity as well as significant degradation. Amin et al. (2014) stated that strain energy depends on the displacement on all degrees of freedom of the structure as well as the values of all forces on the structure. They also added that near-fault ground motion has unique properties 
causing structure to dissipate earthquake input energy in a few large deformation cycles compared to far-fault ground motion. Structural damage caused by far-fault earthquake was contributed by low-cycle fatigue effects and maximum strain.

During earthquakes, there was a critical after-effect that occurs resulting in losses of life's, injuries, failure of buildings, collapse of structures, disruption of the electricity, fires and others. Different failure modes occur at different seismic impacts and it depends on the level of earthquake excitation whether is low, medium or high. Murat (2011) investigated the damages after earthquake and found that the failures were collapsed of ground story in soft-story mechanism and column failures with buckling of longitudinal rebar and opened ties. Furthermore, the damages were found to be caused by a few reasons namely soft and weak story mechanism, pounding effect, poor concrete quality and unreinforced structural elements. In seismic region, analyzing the building after earthquake by categorizing it using damage index is important to determine the retrofitting method. Furthermore, structural performance of each building should be evaluated properly to investigate the structural safety because it may cause further damage and structural performance or stiffness degradation due to an impact of the seismic ground motion ( $\mathrm{Li}$ et al., 2013; Moreno-Gonzalez \& Bairan, 2013; Ismail \& Ismail, 2017; Ismail \& Abdul Karim, 2017; Anudai et al., 2016; Ismail et al., 2018; Ismail et al., 2018).

Other than that, Shiwua and Rutman (2016) explained that the value of the seismic input energy into the system from seismic excitation differs significantly, depending on the method used where the initial design stage does notunderestimate the input energy as it undermines the provision of desired ductility, which in turn govern the seismic resistance. The procedure proposed a regular evaluation of the seismic input energy above the real values with reasonable margin of safety, excluding the possibility of underestimating the desired ductility. This procedure is performed without recourse to dynamic analysis and it is a convenient tool for the selection of key design parameters at the initial design stage. Based on the definition of seismic input energy proposed, a relationship is established between deformation and total cyclic displacement, and low cycle fatigue criteria. These sets of proposed formulae and methods allow us to assess the behavior of a structural system from earthquake.

Figure 1 shows the location map of the earthquake area in Sabah. Shaded relief model of Sabah and main earthquake locations from 1911 to 2009 are depicted by circles of different sizes highlighting the magnitude on the Richter scale. Variation in filled colour of the circles denotes the depth of the epicenter. Earthquakes of June 2015 that originated from a depth of $12 \mathrm{~km}$ were indicated by circles with red outline. White dashed-line delineates the Western Cordillera. Major faults were shown in black and were based on Pubellier and Morley 103 (David, 2017). Understanding the behavior of earthquake excitations and plate movement is important to evaluate the impact towards the reinforced concrete structural design.

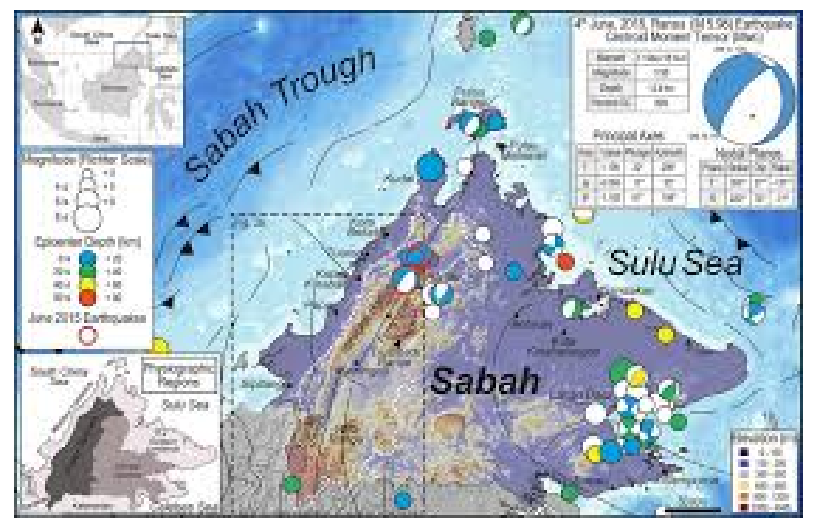

Figure 1. Ranau Earthquake on June 2015 (David, 2016)

In earthquake design, Al-Aghbari et al. (2012) found that for the wall-slab connection design, the anchorage bracing connection can resist earthquake loading better than cross-bracing connections where it is recommended to the construction industry to adopt this design together with the detailing which consists of double layer of wire fabric at the connections. Furthermore, the anchorage bracing connection has better seismic performance as compared to cross-bracing connection under lateral cyclic loading. In order to avoid redistribution of forces from wall panel to floor slab, the connection should be designed with enough percentage of reinforcement, and by considering stress concentration at the jointing system (Pantazopoulou \& Imran, 1992). It is also suggested retrofitting method by using polyurethane coatings to reduce corrosions that may reduce strength of the structure (Dacuan et al., 2021).

Therefore, this study was developed to analyze the work and energy performance of Kolej Delima UiTMPP buildings that were not designed in accordance with earthquake code of practice under four (4) different earthquake records which are Kunak Earthquake, Bukit Tinggi Earthquake, El-Centro Earthquake and Pacoima Dam Earthquake. 


\subsection{Past Earthquake Record in Year 2020 and 2021}

Table 1 shows the past earthquake records that occurred nearby Malaysia and in Sabah. The data were extracted from Volcano Discovery website 2021. The data show the frequency of earthquake's occurrence in Malaysia.

Table 1. Earthquake History in Malaysia Year 2020 and 2021 (Volcano Discovery, 2021)

\begin{tabular}{|c|c|c|}
\hline Date & $\begin{array}{c}\text { Magnitude } \\
\text { (Richter Scale) }\end{array}$ & Location \\
\hline $9 / 3 / 2021$ & 4.6 & $\begin{array}{c}\text { Sulu Sea, 108 km West of } \\
\text { Jolo, Philippines. }\end{array}$ \\
\hline $17 / 2 / 2021$ & 4.5 & $\begin{array}{c}74 \mathrm{~km} \text { North of Tarahan, North } \\
\text { Kalimantan, Indonesia. }\end{array}$ \\
\hline $9 / 9 / 2020$ & 4.8 & $78 \mathrm{~km}$ West of Tawau, Sabah \\
\hline $4 / 7 / 2020$ & 4.6 & $\begin{array}{c}75 \mathrm{~km} \text { East of Lahad Datu, } \\
\text { Sabah }\end{array}$ \\
\hline $30 / 6 / 2020$ & 5.1 & $\begin{array}{c}\text { South China Sea, 24km North } \\
\text { of Pulau Mantanani Besar, } \\
\text { Sabah. }\end{array}$ \\
\hline $15 / 4 / 2020$ & 4.4 & $\begin{array}{c}38 \mathrm{~km} \text { East of Lahad Datu, } \\
\text { Sabah. }\end{array}$ \\
\hline $14 / 4 / 2020$ & 4.9 & $\begin{array}{c}32 \mathrm{~km} \text { East of Lahad Datu, } \\
\text { Sabah. }\end{array}$ \\
\hline
\end{tabular}

The past earthquake records in Malaysia show the frequency of earthquake excitation in Malaysia. The data show the magnitude was recorded between 4.4 to 5.1 Richter Scale which is in the medium range of earthquake but high region in Malaysia. It is because Malaysia is not exposed to earthquake before, and with this range of magnitude, it was found to cause damage to the structure constructed at this area.

\section{Methodology}

Methodology of work and energy analysis involved preliminary design of reinforced concrete structure in order to design the structure and check the overall structural performance under normal design without applying earthquake load requirement as shown in Figure 2. The reinforced concrete building namely Kolej Delima UiTMPP was designed using Esteem 8 software with code-based design of BS8110. All the parameters and design specification for beam, slab, column, wall and pile cap that were utilized in this reinforced concrete design of the building used framing system that involved slab, beam, column and foundation. Figure 3 shows the overall 3D model of Kolej Delima UiTMPP using ESTEEM 8.

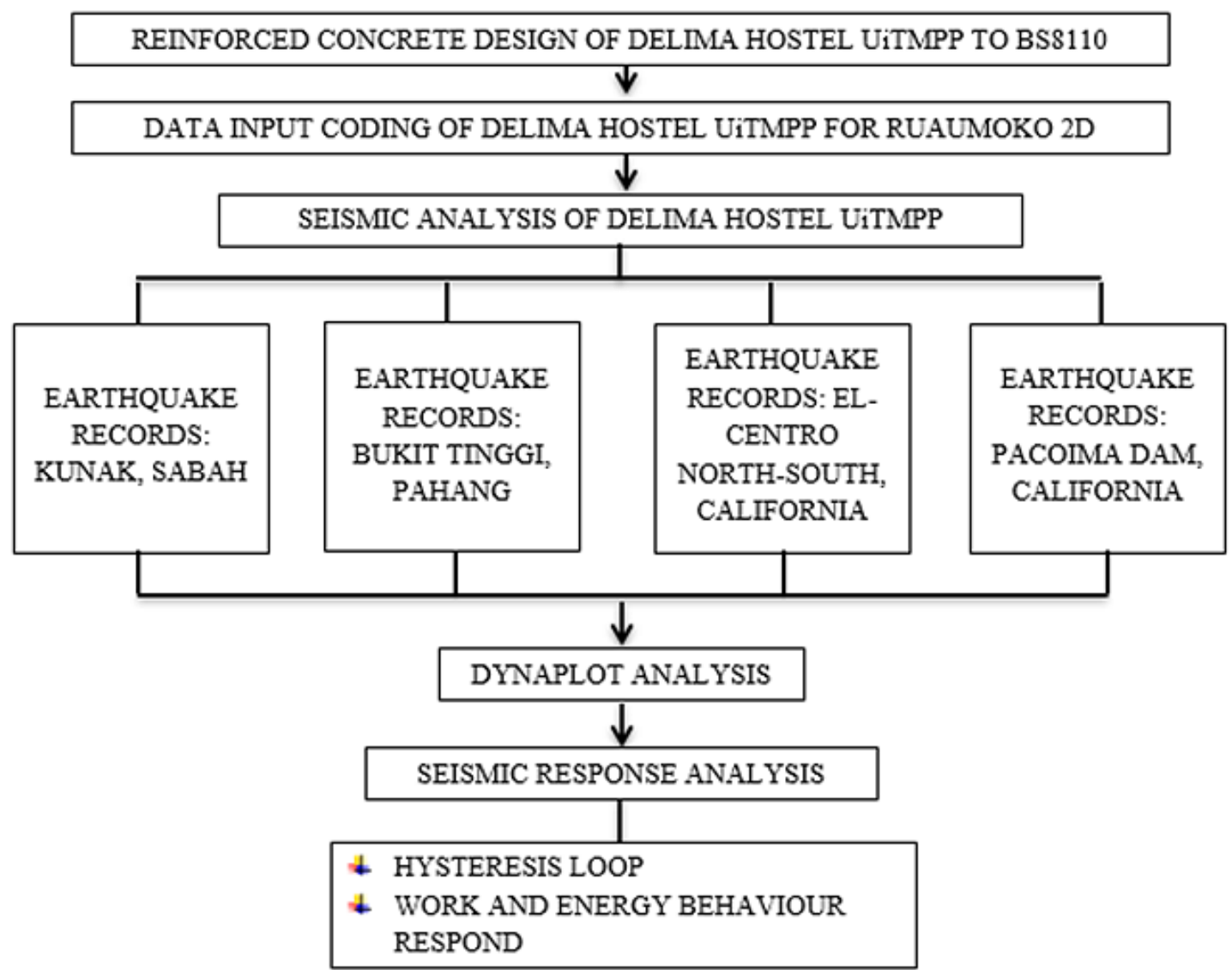

Figure 2. Flow on Analysis of Work and Energy Response using Ruaumoko 2D 


\subsection{Past Earthquake Records Adopted in Analysis}

In order to analyze the structural performance of Kolej Delima UiTMPP under earthquake excitations, four (4) different past earthquake records were adopted in this study with different earthquake excitation level between low, medium and high. The chosen past earthquake records in this study covered both local and outside cases. It is important to use different past earthquake records to determine different performance of work and energy dissipation for Kolej Delima UiTMPP. Table 2 shows the past earthquake records that were adopted as data in Ruaumoko 2D program for different levels of peak ground acceleration (PGA) to examine the work and energy performance of the building structure.

Table 2. Past Earthquake Record Adopted

\begin{tabular}{|c|c|c|c|}
\hline Location & Magnitude & PGA (g) & Reference \\
\hline Kunak & 5.0 & 0.0065 & \\
\cline { 1 - 3 } Bukit Tinggi & $2.2-3.9$ & 0.000464 & \multirow{2}{*}{$\begin{array}{c}\text { Ghani et al. } \\
2013\end{array}$} \\
\cline { 1 - 3 } El-Centro & 7.1 & 0.348 & \\
\cline { 1 - 3 } Pacoima Dam & 6.6 & 1.19 & \\
\hline
\end{tabular}

\subsection{Modelling of Kolej Delima UiTMPP}

Figure 3 shows the overall 3-dimensional model of Kolej Delima UiTM Pulau Pinang that consists of 10 stories buildings using industrial building system (IBS) as the method of construction and structural components. This building was designed using BS8110 as the code of practice before being transferred into Ruaumoko 2D for the analysis under earthquake loads and excitations. The structure should design and fulfil the requirement of ultimate and serviceability limit state to ensure basic structural performance passes the required design stages. Furthermore, the results or variables of loading on beams and moments at column were important to be extracted as the input data in Ruaumoko 2D for further analysis on work and energy performance of the building under different earthquake excitations.

The reinforced concrete structural design specification was determined as stipulated in the architectural drawing provided by Civil Engineer from the Office of Facility Management, UiTM Pulau Pinang. The specification was determined in this study following the original design to determine the specific variables under ultimate and serviceability limit stage.

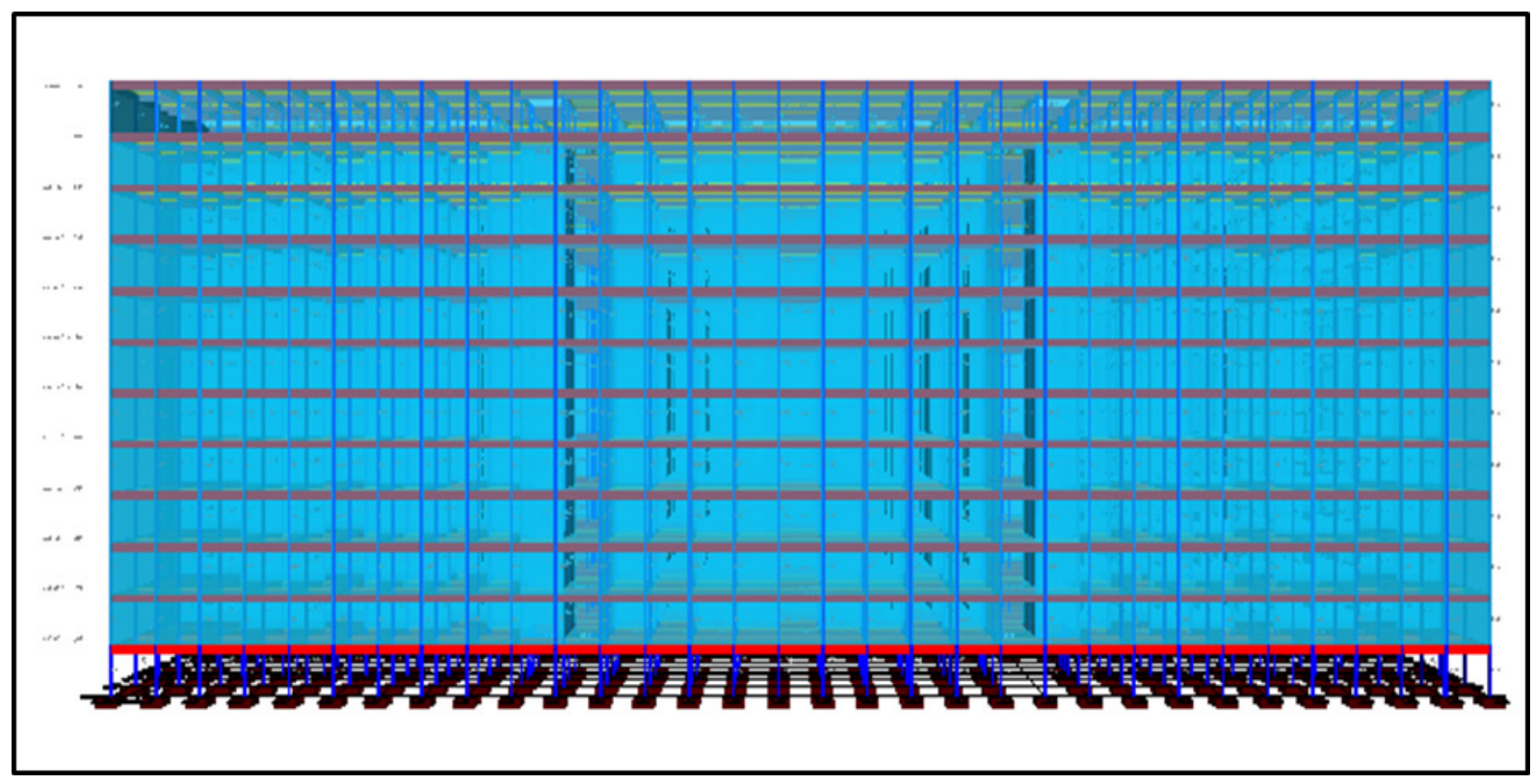

Figure 3. 3-Dimensional Model of Kolej Delima UiTMPP 


\subsection{Analysis of Work and Energy}

The analysis of work and energy for earthquake structure to determine the damage pattern of the structure which is, equivalent to viscous damping is important to be studied because it reflects the drift level of the structure based on the earthquake excitations. Equivalent viscous damping (EVD) ratio is defined as a function of displacement ductility under the crucial parameter in the application of the control displacement method. For the reinforced concrete wall-slab connections under complete one cyclic loading, EVD ratio was derived based on their hysteretic response and hysteretic energy dissipated under fully reversed cyclic loading. The equivalent viscous damping ratio for anchorage and cross bracing connections was calculated based on the area under hysteresis loops for each drift. EVD reflected the result and performance of the structure in producing the work and energy dissipation of the structural system.

Table 3 shows the values of earthquake excitations from four (4) past earthquakes that were adopted in this study. Equation 1 shows the formula used to determine the earthquake excitations.

$$
\text { Excitation }\left(\mathrm{m} / \mathrm{s}^{2}\right)=\text { PGA } x \text { gravity }
$$

Table 3. Earthquake Excitations

\begin{tabular}{|c|c|c|}
\hline Earthquake & Excitation $\left(\mathrm{m} / \mathrm{s}^{2}\right)$ & Region \\
\hline Kunak & 0.06377 & Low \\
\hline Bukit Tinggi & 0.004513 & Low \\
\hline El-Centro & 3.414 & Medium \\
\hline Pacoima Dam & 11.674 & High \\
\hline
\end{tabular}

Work and energy analysis took place in order to determine the overall performance of the structure failure modes. In this study, a few parameters need to be determined as preliminary data in coding format such as nodes, elements, weight, loads and section properties as the input in Ruaumoko 2D. All the steps to prepare the data to be used in Ruaumoko 2D software were determined from Ruaumoko Manual Volume 2: User Manual for the 2-Dimensional Version Ruaumoko 2D by Athol J. Carr. Figure 3 shows the nodal assignment for the 2D Ruaumoko model of Kolej Delima UiTMPP to produce seismic performance of the structure. In this study, a total of 693 nodals were assigned for the whole buildings as a reference point to analyze the overall structural performance under earthquake excitations that have been chosen for this study as shown in Figure 4. The analysis of work and energy analysis was determined at each nodal in order to develop the overall energy dissipation from the structural system due to the earthquake excitation applied.

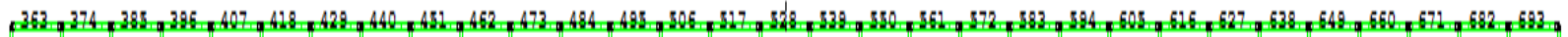

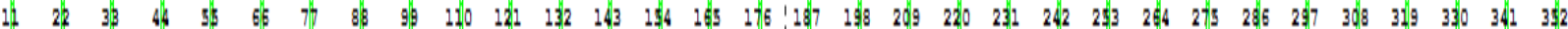

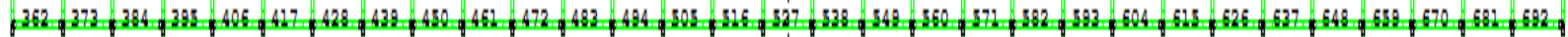

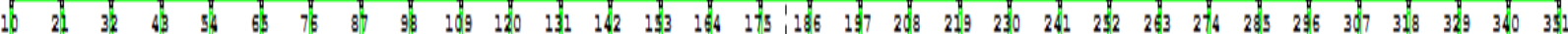

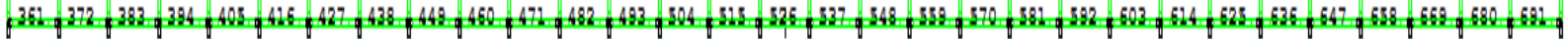

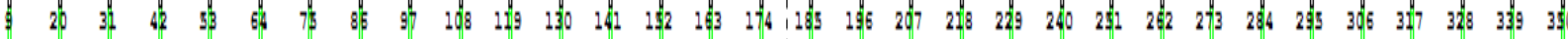

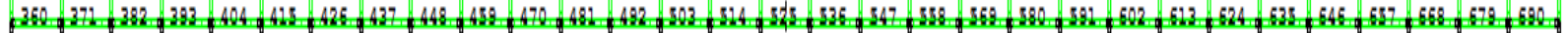

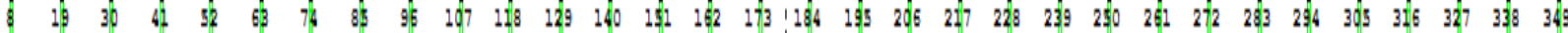

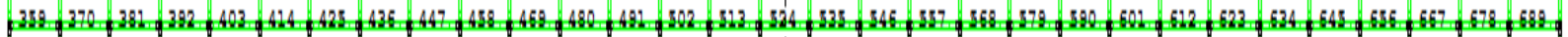
$\begin{array}{lllllllllllllllllllllllllllllll}18 & 29 & 40 & 52 & 62 & 73 & 84 & 95 & 106 & 117 & 128 & 139 & 190 & 161 & 172 & 183 & 194 & 205 & 216 & 227 & 238 & 249 & 260 & 271 & 282 & 293 & 304 & 315 & 326 & 337 & 348\end{array}$

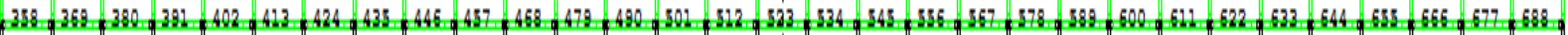

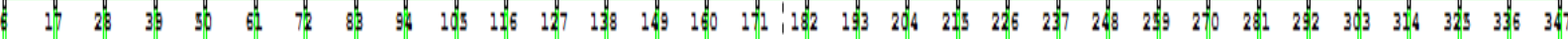

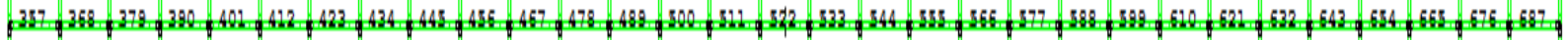

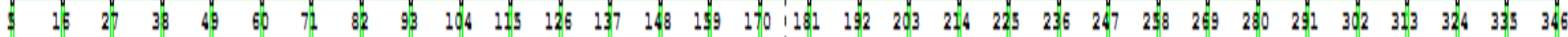

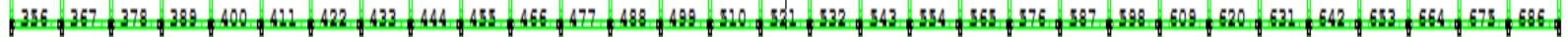

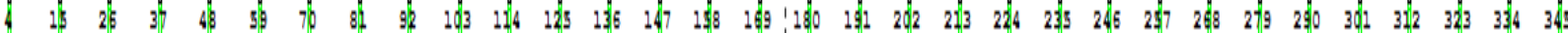

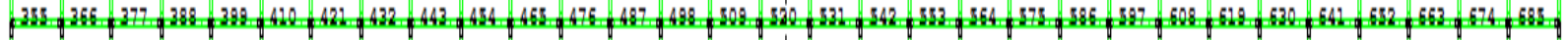

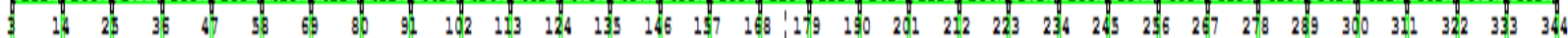

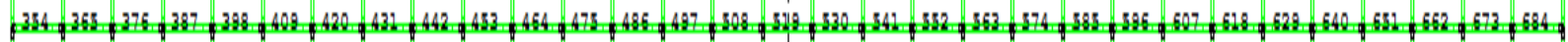

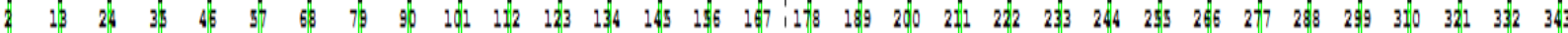

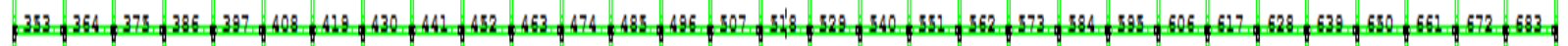

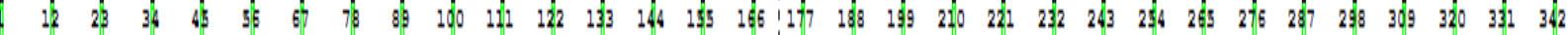

Figure 4. Nodal Assignment Modelling of Kolej Delima UiTMPP 


\section{Results and Discussion}

The results and discussion of this study explain the overall performance of the prefabricated reinforced concrete structure under hysteresis loop, work and energy behavior of Kolej Delima UiTMPP under four past earthquake excitations records. Furthermore, it also compares the behavior of work and energy parameters obtained in earthquake design analysis based on past earthquake records.

\subsection{Hysteresis Loop}

Hysteresis loop is a relationship produced by load-displacement behavior of the structure under applied load. Although hysteresis loop was possible to be presented by each nodal assigned in the simulations, the analysis that has been chosen in this study was only at the maximum nodal that produces the highest displacement behavior of the applied earthquake excitations for each past earthquake record. Based on the analysis done, it was found that all four cases produced the maximum displacement at Node 353 that was located at roof floor.

Figure 5 shows the hysteresis loop for Kolej Delima UiTMPP under Kunak, Sabah earthquake excitations. Based on the results for, this earthquake excitation, it shows the maximum pulling load was recorded at 0.06979 $\mathrm{kN}$ with maximum displacement of $0.4175 \mathrm{~mm}$. Load of the structure is inversely proportional to the position of the node. The higher the node, the smaller the load on the structure but for displacement, it is directly proportional to the position of the nodes. Displacement value for node is increasing as the position of the node increases. Hence, there was no pushing load recorded due to unaffected condition of the building towards the earthquake.

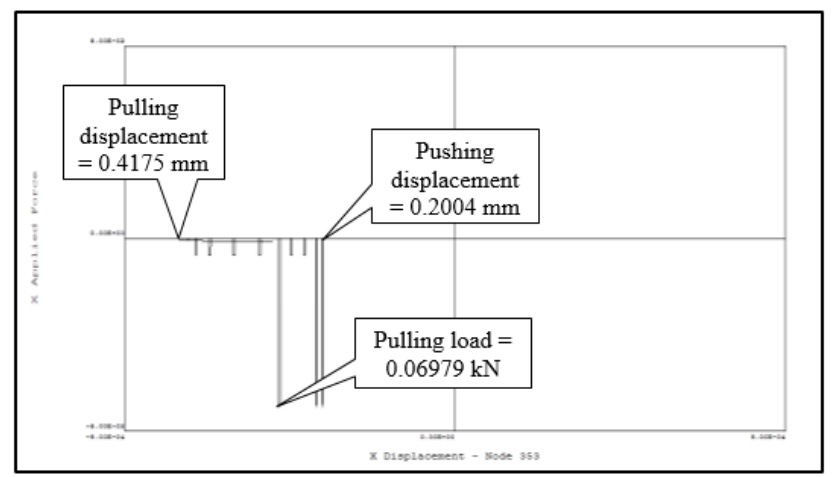

Figure 5. Hysteresis Loop under Kunak Earthquake Excitation

Figure 6 shows the hysteresis loop for Kolej Delima UiTMPP under Bukit Tinggi, Pahang earthquake excitations respectively. The hysteresis loop graph for this case shows that the building was not affected under this past earthquake records because of the low Peak Ground Acceleration 0.000464 g. Under this condition, the building was not facing any structural failures and under normal condition after vibration impact. Similar to the above case, under these earthquake excitations, it only behaves in pulling performance and not in pushing because the structure is able to sustain pushing load compared to pulling load. Under normal design of reinforced concrete structure at low seismic region, the building does not lose its structural integrity and stiffness because the structural members are able to provide resistance for the vibration due to low earthquake excitations.

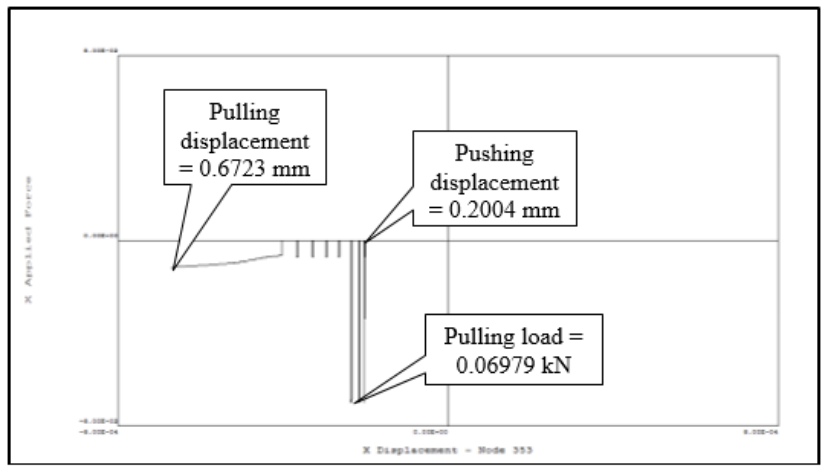

Figure 6. Hysteresis Loop under Bukit Tinggi Earthquake Excitation

Figure 7 shows the hysteresis loop of Kolej Delima UiTMPP under El-Centro earthquake excitations. El-Centro earthquake was considered as a medium earthquake excitation with Peak Ground Acceleration of 0.348 g. The Peak Ground Acceleration determines the vibration of the earth crust that causes the structural failure of the building. Under El-Centro earthquake, it was found that the maximum pushing load was recorded at $1872 \mathrm{kN}$ and the maximum pulling load was recorded at $2431 \mathrm{kN}$. Besides that, significance displacement under this earthquake excitation for Kolej Delima UiTMPP was recorded at $464.8 \mathrm{~mm}$ in pulling displacement and 212 $\mathrm{mm}$ in pushing displacement.

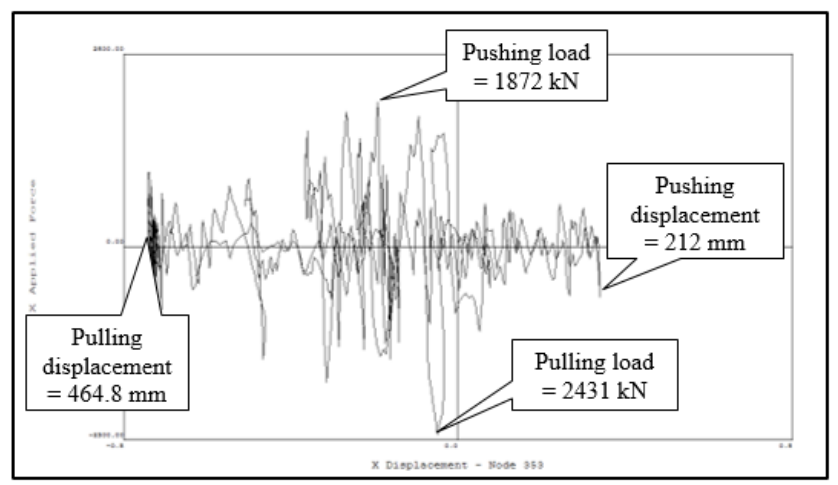

Figure 7. Hysteresis Loop under El-Centro Earthquake Excitation

Figure 8 shows the hysteresis loop for Kolej Delima UiTMPP under Pacoima Dam earthquake excitations. Based on the analysis, it was found that the load of a structure was inversely proportional to the position of the 
node. The higher the node, the smaller the load on the structure but displacement was directly proportional to the positions of the node. It was recorded that the maximum pushing load under this experience was $8168 \mathrm{kN}$ and the maximum pulling load was $6065 \mathrm{kN}$. Hence, the maximum displacement record at this node was $518.4 \mathrm{~mm}$ for pushing and $624.4 \mathrm{~mm}$ for pulling behavior. Hysteresis loop represented the overall behavior of the structural system under damping factor and earthquake accelerations. It is also important to monitor the residual load produced from the results in order to determine the structural strength after impact.

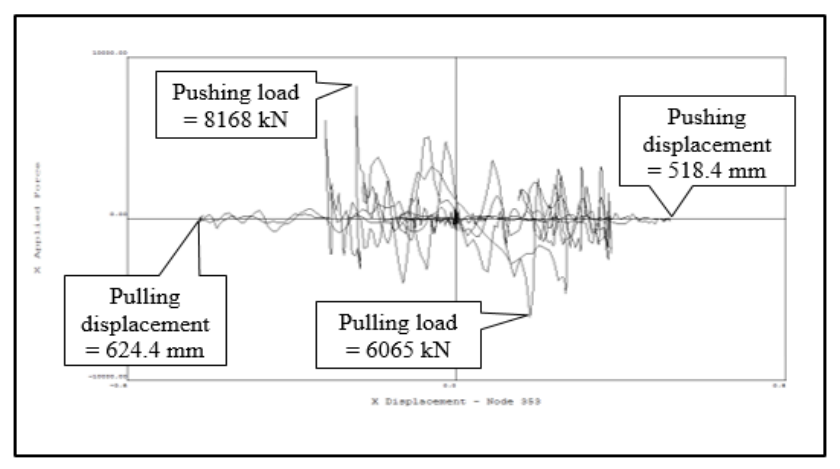

Figure 8. Hysteresis Loop under Pacoima Dam Earthquake Excitation

\subsection{Work and Energy Response}

Work and energy response analysis of the building is important to develop the structural performance under earthquake phenomenon. Based on the four parameters in the analysis of work and energy behavior, Pacaimo Dam earthquake excitation produced the highest work and energy values for Kolej Delima UiTMPP in all four behavior conditions. Figure 8 shows the work and energy behavior of Kolej Delima UiTMPP under four different past earthquake excitations. Under Kunak earthquake, Kolej Delima UiTMPP was found to be stable and faced very low energy dissipation which was similar to Bukit Tinggi earthquake compared to El-Centro earthquake and Pacoima Dam earthquake. The graph presents four different lines namely blue, green, red and black. Blue colour line represents the applied work done on the structure, green colour line represents kinetic energy with damping work and strain energy, red colour line represents kinetic energy plus damping work, and black colour represents the relative kinetic energy of the structure.

It produced the maximum of $314.63 \mathrm{~kJ}$ energy dissipation under relative kinetic energy, $317.83 \mathrm{~kJ}$ under kinetic energy with damping work, $322.53 \mathrm{~kJ}$ under kinetic energy with damping work and strain energy, and $322.78 \mathrm{~kJ}$ under applied work done. It produced 630 times higher than Kunak and Bukit Tinggi earthquake. The difference reflected the damages that occur in the building under those applied earthquake excitations. The highest energy dissipation caused more damages to the structure including failure of the main structure such as column, beam, slab and foundation. Furthermore, the pattern of the work and energy relationship of each case determined the level of seismic region.

Therefore, it was determined that Kunak and Bukit Tinggi earthquake were two new regions that experienced earthquake tremor and categorized under low seismic region because their locations are far from the nearby fault line i.e. Sumatera and Sunda fault lines. Figure 9(a) and Figure 9(b) produce almost the same performance of strain and kinetic energy with damping work and strain energy. Therefore, the proposed source energy formulation with kinetic energy can be used to convert the GPS-derived earth-quake information into tsunami energy and to detect tsunami scales for early warnings in practice as stated by Song et al. (2017). In fact, a GPS approach has been tested in a NASA pilot program of the GPS-aided Real-Time Earthquake and Tsunami (GREAT) Alert System, as reported by Naranjo (2013), and its real-time performance.

It can be concluded that work and energy response analysis of earthquake does not only produce the value of load release that affects the external behavior but it also affects the internal behavior of the structural system such as kinetic energy, applied work done and energy dissipation. 


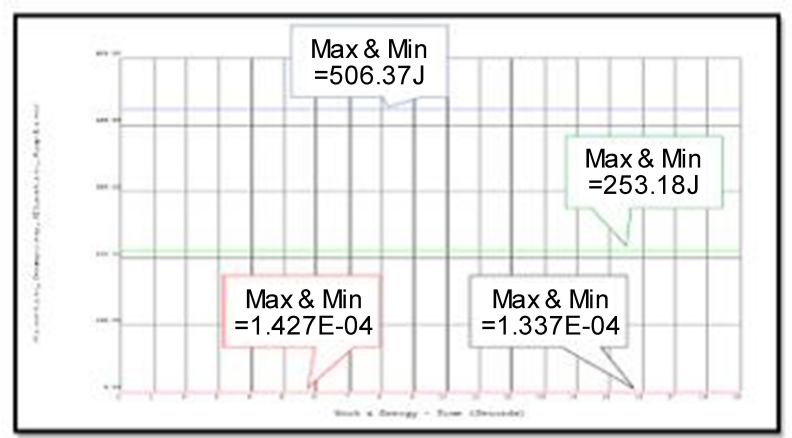

(a)

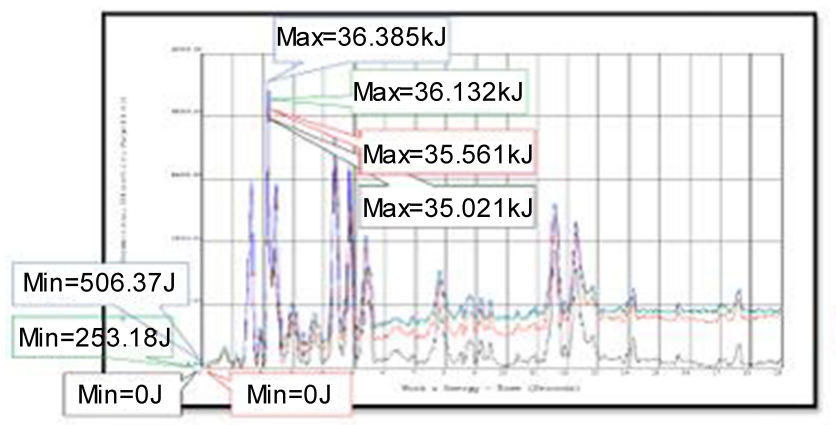

(c)

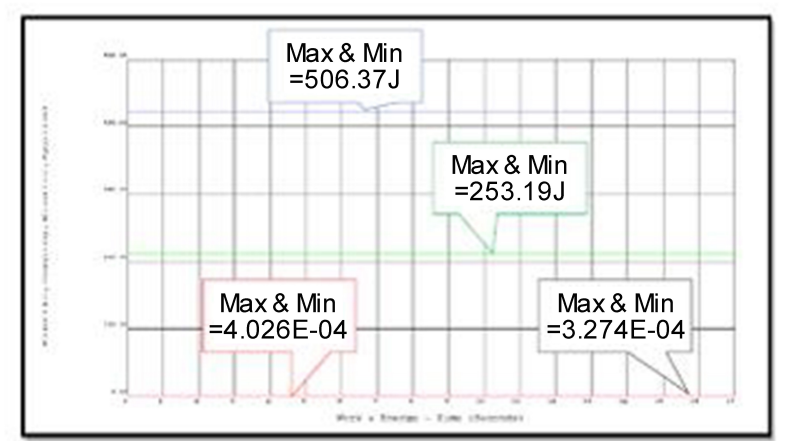

(b)

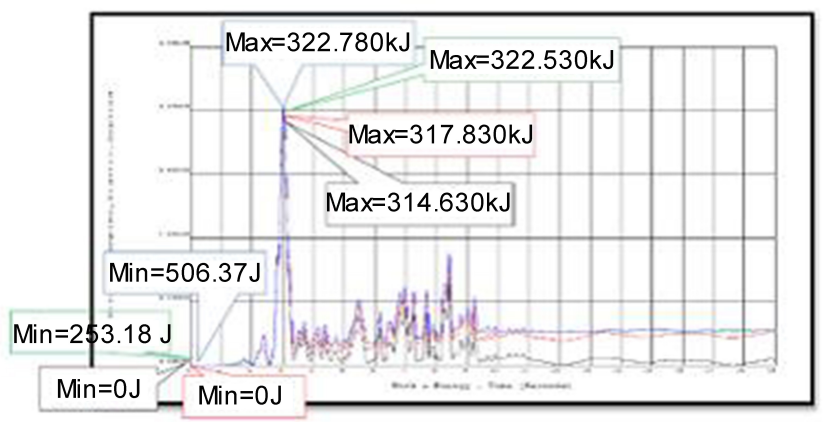

(d)

Figure 9. Work and Energy Behavior of (a) Kunak Earthquake; (b) Bukit Tinggi Earthquake; (c) El-Centro Earthquake; (d) Pacoima Dam Earthquake

\subsection{Displacement Behavior}

The prefabricated concrete structure or known as industrialized building system used as structural components for Kolej Delima UiTM Pulau Pinang was found to be the best decision although it was not designed under earthquake load. It is because in this system, shear wall acts as a component that resists the load due to vibration and becomes a stiffness of the building when excessive load occurs. Therefore, the building was found to have minor damages under moderate earthquake excitation that have not caused any structural integrity problems. The energy dissipation of this building is being absorbed by the reinforcement of the shear wall which is transferred to beam, column, foundation and distributed to the ground during the tremor.

Figure 10 shows the displacement behavior of Kolej Delima UiTM Pulau Pinang under Pacoima Dam earthquake excitation. Severe damage with large displacement at the maximum of $512 \mathrm{~mm}$ occurred at critical joint of building which was slab-wall connection and slab-beam connection. Based on their performance, an investigation of the building for retrofitting is important to ensure the building that has suffered from an earthquake impact is being stiffened to its requirement of structural performance in terms of ultimate and serviceability limit state. The best retrofitting method should be suggested based on the analysis after impact and level of building severity either under functional, minor damage, moderate damage or severe damage.

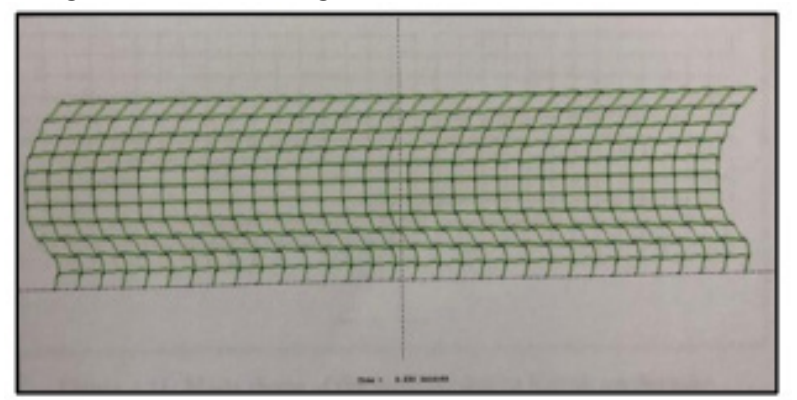

Figure 10. Displacement Mode Shape of Kolej Delima UiTMPP under Pacoima Dam Earthquake Excitations

\section{Conclusions}

In conclusion, this study found that work energy analysis of reinforced concrete structure after an earthquake impact is important to determine the strength of the building. Furthermore, the relationship of work and energy dissipation in earthquake impact is relevant to explain the need of retrofitting work and classify the damage categories. Other than that, under medium region earthquake excitation, Kolej Delima Hostel UiTMPP was discovered to be partially damaged because the building was not designed according to the earthquake code of practice. Furthermore, this study is a sign of awareness in the implementation of earthquake design in reinforced concrete structure in order to protect the occupants from 
any possible occurrence of earthquake. Besides that, this study has developed a new justification for factor of safety in reinforced concrete design and additional action analysis in design action of the structure despite the dead load and live load only. Environmental exposure and accidental load are also new parameters that should be included in the load analysis for designing reinforced concrete structure. Therefore, understanding new behavior of surrounding environment is an important parameter for the structural safety factors.

\section{Acknowledgments}

We are very grateful to express our thanks and gratitude to Universiti Teknologi MARA, Cawangan Pulau Pinang for funding this research and publication.

\section{REFERENCES}

[1] A. A. N. Al-Aghbari, S. H. Hamzah, N. H. A. Hamid, N. A. Rahman. Structural Performance of Two Types of Wall Slab Connection Under Out-Of-Plane Lateral Cyclic Loading. Journal of Engineering Science and Technology Vol. 7, No. 2: 177 - 194. 2012.

[2] A. J. Shiwua and Y. Rutman. Assessment of Seismic Input Energy by Means of New Definition and the Application to Earthquake Resistance Design. Journal of Architecture and Engineering. 2016.

[3] Analysis, Numerical Computations, Codified Methods, Case Studies and Examples. Springer-Verlag Berlin-Heidelberg, German. 2011.

[4] C. N. Dacuan, Virgilio Y. Abellana, Hana Astrid R. Canseco, Minerva Q. Cañete (2021). Hydrophobic Polyurethane Coating against Corrosion of Reinforced Concrete Structures Exposed to Marine Environment. Civil Engineering and Architecture, 9(3), 721 - 736. DOI: 10.13189/cea.2021.090314.

[5] E. Pantazopoulou and I. Imran. Slab-wall connections under lateral forces. ACI Structural Journal, 89(5), 515-527.1992.

[6] G. Li, Y. Zhang and Li. Seismic Damage Analysis of Reinforced Concrete Frame Using the Force Analogy Method.” J. Eng. Mech., 139(12), 1780-1789. 2013

[7] K. D. A. Ghani, N. H. A. Hamid and M. S. Jaafar. Load versus Displacement Validation between Ruaumoko Hysteresis Program and Experimental Work on CFRP Retrofitted Precast Beam-Column Exterior Joint. Journal of Key Engineering Materials 594-595:390-396. 2013

[8] L. Naranjo. Sizing a tsunami, in Sensing Our Planet, NASA Science Research Features, edited by J. Beitler, pp. 30-33.
2013.

[9] M. David, M. Mathew, M. Pubellier, F. Sapin, B. Delcaillau, N. Siddiqui, M. Ramkumar, M. Santosh. Landscape Response to Progressive Tectonic and Climatic Forcing in NW Borneo: Implications for Geological and Geomorphic Controls on Flood Hazard. Scientific Report 7:457. 2017.

[10] Moreno-Gonzalez R. \& J. M. Bairan. Seismic Damage Assessment for Waffled-Slabs Reinforced Concrete (RC) Buildings in Barcelona, International Journal of Architectural Heritage: Conservation, Analysis, and Restoration, 7(1). 2013

[11] O. Murat. Field Reconnaissance of the October 23, 2011 Van Turkey Earthquake: Lessons from Structural Damages. Journal of Structural Engineering, 41: 1-15. 2011.

[12] Online Available: https://www.volcanodiscovery.com/earthquake-monitor.ht m

[13] P. Segupta and B. Li. Hysteresis of Reinforced Concrete Walls. Journal of Structural Engineering, 140: 1-18. 2014.

[14] R. Ismail and M. I. Ismail. Dynamic analysis of Concrete Faced Rockfill Dam using Finite Element Method. Journal of Engineering and Applied Sciences, 12(7), 1772-1776. DOI: $10.3923 /$ jeasci.2017.1772.1776. 2013

[15] R. Ismail and M. R. Abdul Karim. Concrete bridge pier performance under earthquake loading. Journal of Engineering and Applied Sciences, 12(9), 2254-2258. DOI: 10.3923/jeasci.2017.2254.2258. 2017

[16] R. Ismail, A. Ibrahim and A. Adnan. Damage Assessment of Medium-Rise Reinforced Concrete Buildings in Peninsular Malaysia Subjected to Ranau Earthquake, International Journal of Civil Engineering and Technology, 9(7), pp.881-888. 2017

[17] R. Ismail, A. Ibrahim, M. Rusop and A. Adnan. Determination of Mechanical Properties Natural Rubber Compounds Using Double Shear Test Pieces. International Journal of Civil Engineering and Technology, 9(8), pp. 37-43. 2018

[18] R. Ismail, A.Ibrahim, H.Hamid, M.Rusop, A. Adnan. Experimental study on mechanical properties of elastomer containing carbon nanotubes. Journal of Engineering Science and Technology, Vol. 13, No. 3 656-664. 2018.

[19] S. Amin, S. B. Beheshti-aval, M. Ala. New Energy Based Approach to Predict Seismic Demands of Steel Moment Resisting Frames Subjected to Near-fault Ground Motions. Engineering Structures, 72: 182-192. 2014.

[20] S. Anudai S, N. H. A. Hamid, M. H. M. Hashim. Experimental Study on Seismic Behavior of Repaired Single and Double Unit Tunnel Form Building Under In-Plane Cyclic Loading Malaysian Construction Research Journal, 19 (2), 19-28. 2016

[21] Y. T. Song, A. Mohtat, and S. C. Yim. Research Articles: New Insights 0n Tsunami Genesis and Energy Source. Journal of Geophysical Research: Oceans: 122. 2017. 